\title{
LAS VOCACIONES EN LA IGLESIA, HOY
}

DOI: https://doi.org/10.52039/seminarios.v56i197-198.400

Alonso MORATA MOYA ${ }^{1}$

\begin{abstract}
El autor nos recuerda que Nuevas vocaciones para una nueva Europa está en plena sintonía con el gran programa de acción pastoral que viene demandando para sí la Iglesia del Viejo Continente. La pastoral vocacional se ha de reconocer como transversal al resto de acciones pastorales de la comunidad cristiana. De cómo se afronte hoy este convencimiento depende, en no poca medida, que la Iglesia europea pueda renovarse, tomar aire y seguir exhalando el Espíritu de Dios en medio de una tierra que necesita hacer memoria de su fe.
\end{abstract}

\section{ENCUADRE}

En el $n^{\circ} 13$ del documento final del Congreso Europeo de Vocaciones, In verbo tuo; más conocido como Nuevas Vocaciones para una nueva Europa, se nos dice: "Se impone en este momento, un razonamiento nuevo sobre la vocación y las vocaciones, sobre la cultura y la pastoral vocacional». Continúa señalando que hay que provocar una «sacudida» de suficiente envergadura como para abrir tiempos nuevos en nuestras Iglesias.

Teniendo en cuenta el cuadro caracterológico que presenta esta sociedad nuestra en continuo cambio, esta exigencia del documento -cuyo contenido siguió con sumo interés el papa Juan Pablo II, consciente de su importancia-, ha de tener a la comunidad eclesial, especialmente a los animadores de ella, presbíteros, religiosos y laicos, en actitud de vigilancia, persuadidos de que esos tiempos nuevos no es que se hayan dado de una vez por todas, sino que hacen de la dinámica de lo novedoso, concreción de lo «nuevo». Estamos, como dice A. Cencini, en continuo cambio. Y toda la comunidad cristiana comprometida es sujeto y objeto de llamada y respuesta. Hemos de ser «Comunidad de llamados que llama».

Ya el Concilio Vaticano II nos adelanta que «todos los fieles cristianos, de cualquier condición y estado, fortalecidos con tantos y tan poderosos medios de salvación, son llamados por el Señor, cada uno por su camino, a la perfección de aquella santidad con la que es perfecto el mismo Padre $»^{2}$. Y, aunque es verdad que la situación de la humanidad ha adquirido concreciones que no con-

1. Alonso Morata Moya. Sacerdote Operario. Ha sido director del Instituto Vocacional Maestro Ávila y de la revista Seminarios. Formador y rector en varios seminarios, posee una dilatada experiencia en el campo de la pastoral de las vocaciones.

2. Cf. LG 11, § 3 . 
templábamos al finalizar el Concilio, no es menos cierto que esta realidad de «llamada a la perfección» es una constante en la identidad de la Iglesia y, por supuesto, de todos aquellos que la formamos, sea cual sea el ministerio al que haya sido llamado: el ministerio en la familia, el de la comunión o de la caridad, pasando por los ministerios de oración y contemplación, con entrega total de la vida de religiosos y religiosas contemplativas o los ministerios de educación, asistencia, etc.; en la vida activa de la comunidades, religiosas o laicas consagradas, y en el ministerio presbiteral, que debe ser el que armonice todos los carismas de su comunidad, integrándolos en la comunidad de la Iglesia diocesana, para formar la única Iglesia universal, con las peculiaridades con las que cada cultura la enriquece. A decir de San Ignacio de Antioquía es como el «director de la orquesta, que, aunque no sepa cantar, aúna todas las voces para conseguir la melodía».

En el libro La formazione oggi, Fabricio Pieri, citando a H. Alphonso, dice: «Un tema fundamental que encontramos recorriendo la Biblia es el de ser 'llamado por el propio nombre' [...] La conclusión sería simplemente la siguiente: yo no soy uno de tantos en la muchedumbre para Dios; no soy para él un número en la serie ni soy catalogado en un boleto; soy irrepetiblemente único, porque Dios 'me llama por mi nombre'. Esta realidad podría incluso denominarse 'mi identidad personal' o quizás 'mi orientación personal en la vida' o también mi profundo y verdadero 'yo'. Según la Biblia, no obstante, prefiero llamarla 'mi vocación personal'. Es triste el hecho de que hemos limitado el término 'vocación a la llamada al sacerdocio o a la vida religiosa, y quizás hablamos cada vez más de mala gana de la 'vocación' al matrimonio o 'vocación' al laicado. De hecho, en la Biblia la palabra de Dios designa cada llamada a un servicio específico orientación o misión en la vida, como 'vocación' [...] estamos todos suspirando por tener unidad e integración, en particular nosotros, apóstoles activos. [...] No es verdad que cuanto más se avanza en perfección y madurez, se llega a ser más sencillo - una sencillez no de empobrecimiento, sino de riqueza concentrada y profundidad» ${ }^{3}$.

En los últimos tiempos y, dado el descenso notable de vocaciones al ministerio presbiteral, nuestra jerarquía, con toda razón, se ha preocupado 4 por proporcionar a las comunidades de este tiempo «pastores según el corazón de Dios». Tarea en la que ha de colaborar la comunidad. Personalmente estoy convencido de que, si una comunidad no tiene la conciencia de ser «llamada» en

3. F. PIERI, La formazione oggi? Porsi accanto per aiutare a crescere, Roma 2010, 30-31, en nota. El texto citado pertenece a H. ALPHONSO, La vocazione personale. Trasformazione in profondità per mezzo degli esercizi spirituali, Roma 1994, 19.24.

4. La «preocupación» es una actitud lógica, cuando las cosas hay que resolverlas, porque no van según las necesidades de la Iglesia, pero es más encomiable la «ocupación» en la tarea vocacional, promoviendo y animando todas las modalidades de llamada que existen desde el principio en la misma Iglesia apostólica. 
cada uno de sus miembros, difícilmente surgirán los ministerios necesarios, entre los que se encuentra, de manera necesaria, el ministerio presbiteral, la cura de almas en el lenguaje tradicional, el cuidado de atender a los miembros de la misma comunidad con cercanía, como función en la gran familia de Dios, presente en esa familia: «A cada uno... se le otorga la manifestación del Espíritu para común utilidad» (1 Cor 12, 7). «Estos carismas, tanto los extraordinarios como los más comunes y difundidos, deben ser recibidos con gratitud y consuelo, porque son muy adecuados y útiles a las necesidades de la Iglesia», nos dice también el Concilio ${ }^{5}$. La armonía de los carismas y el discernimiento de los mismos es tarea importante, pero hemos de dejar al Espíritu que actúe, colaborar con él y no cerrarnos a sus «orientaciones», cambiándolas por metodologías, o volviendo la vista atrás.

Lo que nos preocupa a quienes, por carisma fundacional, hemos dedicado (ocupado) toda nuestra vida sacerdotal a la misión de suscitar y acompañar a los llamados para el ministerio presbiteral, además de los propios fallos, es que se quiera exclusivizar de nuevo e identificar «vocación» con vocación al sacerdocio ministerial. Ante todo porque nos parece empobrecimiento y vuelta atrás de lo que desde el Concilio, pasando por los grandes pontífices de nuestro tiempo -Pablo VI, Juan Pablo II y el actual Benedicto XVI-, ha supuesto la recuperación del sentido de vocación latente y, muchas veces patente, en la Iglesia primitiva, en la que no hay "competencia» sino «complementariedad» de ministerios y carismas, teniendo, eso sí, como ministerio de la síntesis al ministerio presbiteral. Con la convicción de lo que nos decía el papa Juan Pablo II en Novo Millennio ineunte, 43: «Antes de programar iniciativas concretas, es preciso promover el ministerio de la comunión». Y esto significa promover la espiritualidad de comunión: «espiritualidad de la comunión es hacer espacio al hermano, llevando unos las cargas de los otros y rechazando las tentaciones egoístas que continuamente nos asedian y generan competencia, emulación, desconfianza, celos». Estos (la competencia, emulación, desconfianza y celos) son virus antivocacionales y es preciso por eso que la comunidad los tenga siempre presentes (porque), de otra manera no viven esta espiritualidad de comunión.

Ya lo adelantaba la Constitución Lumen Gentium cuando nos decía «para apacentar el Pueblo de Dios y acrecentarlo siempre, Cristo Señor instituyó en su Iglesia diversos ministerios, ordenados al bien de todo el Cuerpo. Pues los ministros que poseen la sacra potestad están al servicio de sus hermanos, a fin de que todos cuantos pertenecen al Pueblo de Dios y gozan, por tanto, de la verdadera dignidad cristiana, tendiendo libre y ordenadamente a un mismo fin, alcancen la salvación» ${ }^{6}$. Y más adelante: «Los miembros del Pueblo de Dios son llamados a una comunicación de bienes, y las siguientes palabras del após-

5. LG $12, \S 2$.

6. LG 18, § 1. 
tol pueden aplicarse a cada una de las Iglesias: 'El don que cada uno ha recibido, póngalo al servicio de los otros, como buenos administradores de la multiforme gracia de Dios' (1 Pe 4, 10)» ${ }^{7}$.

Durante demasiados siglos el ministro ordenado fue asumiendo funciones que pertenecían al pueblo sacerdotal. El Concilio devolvió los ministerios laicales a esos miembros del pueblo y todos ellos (ministerio presbiteral y ministerios laicales) contribuyen a la edificación de la misma Iglesia, Iglesia que no puede existir sin el ministerio presbiteral. De ahí el empeño que hemos de poner todos, en especial los agentes de pastoral, catequistas, etc., para que, dentro de la comunidad de llamados, se den todos los ministerios precisos para su avance en la predicación del Reino. Y es fundamental que en ella no falten quienes dediquen toda su vida, todas sus fuerzas, todo su hacer al servicio de todo el pueblo: de manera especial los consagrados por la Ordenación Presbiteral que prolonga y especifica la consagración ya recibida en el Bautismo y la Confirmación y los sitúa de forma «peculiar» al frente de la comunidad, no como jefes, sino como servidores. "El que quiera ser el primero entre vosotros, sea vuestro servidor». Nos queda mucho que limar en nuestras formas de estar y actuar en las comunidades que nos son encomendadas, para que el pueblo fiel, sienta la identidad cristiana como el «don mayor» que ha recibido. Para una pastoral vocacional efectiva es necesario que el pueblo sienta su identidad cristiana como nuclear en su ser y estar en medio de este mundo nuestro, tan secularizado y, en ocasiones, tan anticristiano.

Volviendo al Documento NVNE en el mismo $n^{\circ} 13$, citando la Proposición 16 dice: «La Iglesia particular es como un jardín florido, con gran variedad de dones y carismas, funciones y ministerios. De aquí la importancia del testimonio de la comunión entre ellos, abandonando todo espíritu de competencia»; y, asumiendo la proposición 19: «Hay necesidad de apertura a los nuevos carismas y ministerios, sin duda distintos de los habituales. La valoración y el puesto de los seglares es un signo de los tiempos que, en parte, está todavía por descubrir y que se está manifestando cada vez más fructífero».

Juan Pablo, II en el Discurso de apertura del Congreso, dice algo que desde mi punto de vista o aún no hemos asumido con fuerza, o no hemos hallado los medios para ponerlo en activo: nos habla de promover una «nueva cultura vocacional en los jóvenes y en las familias». Ciertamente, es ésta una cultura de la vida, de libertad, de comprensión, fuente de responsabilidad ante la existencia, es cultura de apertura al otro ${ }^{8}$. Precisa que es una cultura que «debe pasar cada vez más de la conciencia eclesial a la civil», porque «la crisis que atraviesa el mundo juvenil revela... que nada ni nadie puede ahogar en el hombre la búsqueda de sentido y el deseo de encontrar la verdad. Para muchos éste es el

7. LG $13, \S 4$.

8. Cf. NVNE 13, b §3. 
campo en el que se plantea la búsqueda de la vocación». Y más adelante prosigue: «La escasez... de vocaciones específicas... es, sobre todo, carencia de conciencia vocacional de la vida, la vocación en particular, o bien carencia de cultura de la vocación ${ }^{9}$. «Esta cultura llega a ser hoy... el primer objetivo de la pastoral vocacional ${ }^{10}$. Nos parece que hemos de partir de este planteamiento para vislumbrar el punto de luz que nos conduzca a la luz más plena del camino «nuevo» de la pastoral vocacional.

\section{UnA PAstoral Vocacional nUEVA: «EL SALTO CUaLITATIVO»}

La invitación del Documento se puede resumir en estas palabras: «La pastoral vocacional en Europa ha llegado a una encrucijada histórica, a un paso decisivo». Y por tanto nos equivocaríamos si quisiéramos imitar acciones pasadas, con el mismo espíritu con el que nuestros buenos párrocos incitaron en nosotros el deseo de responder a la llamada del Señor en un servicio específico, en el ministerio presbiteral. Porque hay que asumir la historia, por lo general llena de entrega, de entusiasmo, de amor al sacerdocio, de tantos y tantos sacerdotes, padres y madres de familia, de religiosos y religiosas, maestros y fieles ejemplares que han puesto en nosotros una semilla que fructificó y sigue dando fruto en la entrega. Pero nosotros mismos, hemos experimentado que nuestra manera de ejercer el ministerio no se parece a la de aquellos mismos cuyo ministerio nos sirvió de mediación para seguir el camino. Yo me atrevería a más: quien quisiera ser sacerdote a la manera «externa» de aquellos, no debería ser ordenado para este mundo de hoy que necesita testigos del Evangelio que se metan en la refriega del mundo, como testigos de otra manera de ver y sentir las cosas, de una moral, que no es un ethos pasajero, sino una forma nuclear de vivir, porque no se es cristiano por profesar una «moral», usos y costumbres, sino que se tiene esa forma de vivir porque se es cristiano. Y ser cristiano no es cumplir unos preceptos, sino actuar siempre bajo el prisma de la caridad, el amor que lleva a cumplir la ley y va más allá de esta misma.

En el mismo número 13, se pone una serie de condiciones que nos sitúan en los principios de una forma nueva de ejercer la pastoral vocacional en la Iglesia de hoy, con un corazón nuevo, con una perspectiva constantemente renovada, que ilusione a los jóvenes en la «aventura» de seguir al Maestro. No otra cosa hicieron los apóstoles: cambiar sus vidas e ir aprendiendo a asemejarse al Maestro. En todos ellos se aprecia un proceso vocacional importante. Por indicar tan sólo dos, les invito a que lean los libros del Cardenal Martini ${ }^{11}$,

9. Cf. $13, b$.

10. Ibid.

11. C. M. MARTINI, El itinerario del discípulo, Santander 1997; ID., La audacia de la pasión. El hombre contemporáneo y el dilema de la acción, Madrid 2008. 
en ellos descubriremos la dinámica del progresivo encuentro, la momentos de plenitud y de desánimo y la presencia de Jesús en ellos. Quiénes llevamos ya cuarenta años intentando ejercer con fidelidad el ministerio sacerdotal presbiteral, somos conscientes de la cantidad de momentos de conversión que han sido necesarios para adaptar nuestra palabra y nuestra acción a la exigencia de ser «evangelizadores» para el mundo de hoy y el saber que no siempre lo hemos conseguido. Que caminamos entre debilidades propias y las fuerzas que el Señor nos presta.

Por eso estamos convencidos de que el salto que hay que dar no es en la «cantidad», sino en cualidad. En el último punto del n. 13, nos dice: «Es tiempo de que se pase decididamente de la 'patología del cansancio' y de la resignación, que se justifica atribuyendo a la actual generación juvenil la causa única de la crisis vocacional, al valor de hacerse los interrogantes oportunos y ver los eventuales errores y fallos a fin de llegar a un ardiente nuevo impulso creativo de testimonio» ${ }^{12}$.

El Documento In verbo tuo (NVNE) se publicó el 6 de enero de 1998. En 2008, tuvimos en Oporto el Congreso Europeo de Vocaciones, promovido para re-actualizar las enseñanzas de éste, para mí, magnífico documento para progresar en nuestra Pastoral Vocacional. El eco habido del mismo ha sido nulo y nos dio la impresión a muchos de los participantes de que se quería pasar un poco de puntillas sobre él para no despertarlo. Y necesitamos una Iglesia valiente en su acción, como son los discursos contracorriente de nuestro actual Pontífice Benedicto XVI, contra leyes y decisiones que van a dañar la vida cristiana. También en nuestro «espíritu» y actuación en la «promoción de nuevas vocaciones» hemos de tener en cuenta que nos encontramos en una nueva Europa, y que el mensaje es para todos los tiempos y para los hombres y mujeres de cada tiempo, lo cual exige las comunidades adecuadas y los guías de las comunidades que impulsen la «novedad» de la Buena Noticia, saliendo al encuentro de los hombres, proponiendo que ser cristiano es "forma de vivir», no conjunto de dogmas que son expresión resumida y asumida de nuestro credo, credo que va más allá de saber unas verdades y recitarlas, para convertirse en oferta de una vida nueva que lleve a la felicidad del hombre. Un convencimiento ha de habitar los principios de toda pastoral vocacional, el que la vida es «don recibido que tiende, por naturaleza, a convertirse en bien donado» (NVNE, 15b) y que este impulso es connatural a todo hombre y mujer, por eso es un servicio que hemos de prestar a todos, de ahí el deseo de responder a esta pregunta: ¿Dónde empezamos a cambiar en nuestra pastoral vocacional para estos nuevos ministros?

12. Instrumentum laboris, 85 (el subrayado del adverbio es mío). 
Si hay algo de lo que estoy convencido es de que sólo formando comunidades se puede poner en marcha esta nueva pastoral, integrando en ellas a todos: desde los más pequeños a los ancianos y que todos tengan el sentir y el actuar como hijos de la Iglesia, que sienten la responsabilidad adecuada a su edad y viven la fe según su grado de madurez. Durante muchos años he tenido la responsabilidad pastoral como educador en diversos seminarios. Muchas veces, sobre todo en mis primeros años de Rector del seminario menor, teníamos sesiones de formación en las que yo me preocupaba por hacerles participar a ellos, que eran los sujetos de la respuesta. Recuerdo que en una de ellas les pedí que escribieran lo que para ellos significaba vocación. De la forma que les pareciera, sentimiento, descripción... Y nunca olvidaré lo que uno de los jovencitos, tenían entre 12 y 13 años, puso: «Vocación es Jesús que pasa, te mira y tú le miras y no puedes hacer otra cosa que seguirlo». Nunca indagué quién escribió aquello, ni sé si perseveró hasta el sacerdocio ministerial o no, pero es, posiblemente, la más bella descripción de llamada y respuesta que me han dado a lo largo de los años, porque en ella no había teoría sino una experiencia vivida por el niño que aquello escribió. Siempre me recordó el capítulo primero de Juan y la llamada de Jesús, tras la indicación del Bautista a Andrés y Juan de que Aquel que pasaba era "el Cordero de Dios que quita el pecado del mundo». Jesús pasa y se van detrás de Él. «¿Qué buscáis?». «Maestro, ¿dónde vives?».

No podemos excluir a los niños de la acción evangelizadora, y demandar de ellos tan sólo el cumplimiento de normas, sino provocar en ellos la experiencia de aquel a quién estoy seguro ellos son ágiles en captar y experimentar como amigo en sus vidas recién estrenadas. Hacerles sujetos de normas sería provocar una respuesta de «obligados», no de «enamorados» y nadie como un niño percibe ese enamoramiento especial de Jesús que les hará responder cualquiera que sea la modalidad vocacional a la que él le llame. Es necesaria una catequesis continuada que no se acabe en la preparación para la Primera Comunión y... si te vi, no me acuerdo; sino que vaya comprometiéndolo al ritmo de su evolución personal, en una vivencia continua y cada vez más profunda del Señor.

En casos concretos esa era la función de nuestros seminarios menores. Ocurre que no siempre hemos acertado a ayudarles a discernir el camino, sobre todo en los momentos de la pubertad y primera adolescencia ${ }^{13}$, en los que la

13. El proceso no acaba, sino que se va acentuando según avanza en el camino, incluso hay que descubrir la importancia del equilibrio afectivo en los ya ordenados. Pero, referido a la vocación como llamada de Dios a cada uno, ha de ser objeto de «educación» toda la vida, aunque la modalidad a la que se sienta uno llamado sea en el matrimonio, en la vida seglar, o vida religiosa. No creamos que está lejos de esta falta de madurez el aumento de separaciones en el matrimonio y la banalidad con la que se considera la vida sexual-afectiva. Nos hemos de preguntar, ¿quiénes son los modelos actuales? 
misma fuerza de su «naturaleza» les hacía perder la perspectiva de la respuesta. Posiblemente no les hayamos educado en el amor, haciendo de esta educación un descubrimiento progresivo. Es verdad que les hemos inculcado el amor a Dios, como no podía ser menos, pero nos ha faltado ayudarles a descubrir que todo sentimiento de amor y donación llevaba, lleva, al amor a Dios, porque de Él procede; y entre ellos está el «enamoramiento» ${ }^{14}$ de una persona que puede complementar su vida, de la mujer, de la chica, como un paso importante para la misma entrega total «a favor de los otros», no porque uno sea una persona «anormal» en su afectividad, sino porque descubre el culmen de esa afectividad en la entrega de todo su amor paterno-filial a los hermanos y hermanas que necesitan de su ministerio dentro de la comunidad a la que pertenece. No por ser alguien rarito, sino, precisamente, por asumir la plenitud del amor y elegirla como culmen del mismo amor que siente por esa persona con la que tendría, quizás, una vida feliz y más o menos cómoda. Uno de mis directores espirituales me decía: «Cuanto más concreta sea la persona, con su nombre y apellidos, más real será la elección que hagas, pero no olvides que esta persona te ha ayudado a salir del amor a ti mismo para encontrar importante el amor a los demás».

Aquí resulta crucial el sentido de pertenencia a la comunidad que vaya adquiriendo y aumentando a lo largo de los años. Llama la atención la fidelidad al "partido» o a "grupos» de pensamiento que muestran los «militantes», y que cada vez se haya perdido más el sentido de militancia como creyentes. No es que me guste la palabra por sus connotaciones guerreras, pero sí por el compromiso que el ser «militante», o sea, persona que vive esa fe con alegría, fuerza, convicción, núcleo de su existencia, etc., comporta. Muchos de los movimientos nuevos en la Iglesia tienen muy claro lo decisivo de inculcar el sentido de pertenencia y, si bien, hemos de rechazar todo aquello que huela a separación o secta, dentro de la comunidad cristiana, es preciso que todos nuestros «bautizados», o la mayor parte, sienta que ellos son la Iglesia, junto con todos los ministros que en ella están al servicio de la comunidad (servidores unos de otros). Más arriba subrayábamos que la jerarquía no es (no debe ser si es jerarquía a la manera de Cristo) sino la que con mayor cuidado y esmero cuida de la comunidad y le presta su servicio, entre el que está no sólo el orientar, sino también el servicio de la escucha, de la acogida, de la paciencia, del situar en la misión correspondiente a todos aquellos que manifiestan su deseo de compromiso más fuerte con la comunidad, siguiendo la vocación a la que han sido llamados dentro de su pertenencia a la Iglesia (comunidad de llamados que, a su vez, llama). Citamos el texto de Mt 9, 37: «La mies es mucha, pero los obreros pocos». «Frente a la mies del Reino de Dios, frente a la mies de la nueva Europa y de la nueva evan-

14. En sentido casi etimológico de entrar a formar parte del amor del otro (in-amore-stare). 
gelización, los 'obreros' son y serán siempre pocos, 'pequeño rebaño y misión grande', para que resalte mejor que la vocación es iniciativa de Dios, don del Padre, Hijo y Espíritu Santo» (NVNE, 13, d). Esto último creo que no debemos olvidarlo nunca en nuestros planteamientos de Pastoral Vocacional.

\section{VOCACIÓN DESDE EL NACIMIENTO Y EL SENTIDO DE LA VIDA}

Quizás una de las primeras cuestiones que hemos de suscitar que se planteen los jóvenes de hoy es la «del sentido de su vida». Hemos creado una cultura juvenil tan dependiente del ocio, de la noche, de la diversión, del mirar sólo hacia fuera, que rara vez el joven de hoy se sitúa ante los interrogantes fundamentales de su vida y, cuando le viene la «tentación» de hacerlo, suele encontrar a alguien que lo persuade de que eso son cosas de "gente antigua». Y es preciso no hacerles nosotros las preguntas, sino "despertar en ellos la pregunta», que el interrogante no provenga del exterior, sino de su propio interior. Pues no es válido esperar a que se encuentre en situación «límite», primero porque esa raramente llega, y se encuentran «a gusto» y felices, cuando creen que se han liberado de la pesada presencia de Dios en sus vidas que tantos padres y curas les han querido inculcar. Hemos creado un clima amniótico en el que se encuentran de maravilla, como si recuperase la seguridad del estar en el seno materno. Hay, de forma paradójica, un deseo de estar en esa situación de felicidad y seguridad, pero, sin la tutela de los padres y en ausencia de referencia al pasado, impide cualquier proyecto de futuro, porque muchos hay que se sienten como si fueran el primero de la especie. Tristemente algunos no son especie única, como decía Unamuno, pero sí «especímenes» que parecen pertenecer a otra raza. Y, lógicamente, al hombre «de a pie» lo consideran un dinosaurio o cualquier otro de los animales prehistóricos. Pasado y fósil.

No es, por supuesto, que los jóvenes no anhelen dar sentido a la vida, por lo general es que les viene «impuesto», "o por lo que se vive de inmediato, o por lo que satisface las necesidades, satisfechas las cuales, la conciencia llega a ser cada vez más obtusa, y las cuestiones importantes quedan eludidas» ${ }^{15}$.

Es una realidad que no podemos eludir, pero el principio está en que no hemos sabido ayudar a que, desde niños, encuentren su identidad y su orientación de vida en la vida de Jesús y en su ilusión y alegría por el evangelio. De hecho los hay que se sienten felices en esta dinámica de vida con y en Jesús y en toda su actitud son «otra clase de jóvenes». Recuerdo en una de las Jornadas Mundiales de la Juventud, que se celebró en Santiago, que las fuerzas del orden estaban maravilladas, porque no tuvieron que hacer ninguna intervención para frenar la violencia, ni hubo levantamientos, ni actos de gamberrismo, y una

15. NVNE, 14. 
pareja de policías municipales me dijo, preguntando, que para eso son gallegos: «Padre, estos jóvenes son de otra clase, ¿verdad?». Ellos sí habían encontrado el sentido de su vida, en cuanto a dirección y contenido que les llenaba. Pero no nos podemos conformar con eso, porque es preciso profundizar más, ayudar a que se abran a todos estos caminos de encuentro, a que descubran que la conversión no es un hecho puntual y concreto en el itinerario personal, sino que es un elemento presente siempre en la dinámica del crecer en Cristo, el Hermano, el Amigo, el Señor.

El proceso que en años pasados era natural, porque la misma sociedad (el clima amniótico de entonces) ayudaba, tiene que ser animado constantemente, y reitero, para que ellos se hagan las preguntas y encuentren, con ayuda de un acompañamiento en escucha, el camino, la vocación a la que Dios les llama, para que sean felices, porque para eso nos ha creado Dios: para la felicidad, no para la norma, sino para saber amar, aunque tengamos que pasar por las dificultades que la vida siempre entraña, especiales para el joven creyente en esta sociedad nuestra, pero no insuperables. «...la comunidad eclesial, por una parte está asida por el misterio de Dios, del que es imagen visible, y, por otra, está totalmente comprometida con la historia del hombre, en situación de 'éxodo', hacia 'los cielos nuevos'. La iglesia, y en ella cada vocación, manifiestan un idéntico dinamismo; ser llamada para una misión» ${ }^{16}$. En esta misión está el sentido profundo de cada una de las vidas, de cada uno de los hombres y mujeres de este mundo, con un sentido muy claro del caminar, del pensar que sólo si no nos detenemos, por miedo o por prudencia, encontraremos la respuesta que, sin duda, Dios nos está ofreciendo ya. Pero nos la ofrece en referencia y desde la comunidad. Nos lo dice también el documento tantas veces citado: «Es también importante que exista una comunidad eclesial que ayude de hecho a descubrir a cada llamado la propia vocación. El clima de fe, de oración, de comunión en el amor, de madurez espiritual, de valor del anuncio, de intensidad de la vida sacramental convierte a la comunidad creyente en un terreno adecuado no sólo para el brote de vocaciones particulares, sino para la creación de una cultura vocacional y de una disponibilidad en cada uno para recibir su llamada personal. Cuando un joven oye la llamada y emprende en su corazón el santo viaje para realizarla, allí, normalmente, hay una comunidad que ha creado las premisas para esta disponibilidad obediente.

Es como decir: la fidelidad vocacional de una comunidad creyente es la primera y fundamental condición para el florecimiento de la vocación en cada creyente, especialmente en los jóvenes ${ }^{17}$. Sin comunidades vivas no es posible dar el salto de «calidad» para unas nuevas vocaciones en esta Europa postcristiana $y$, a veces, anticristiana.

16. NVNE, 15.

17. Cf. Proposiciones, 21 (NVNE, 54). 
No hace muchos días leía la parábola del sembrador y un comentario sobre ella que me pareció muy ilustrativo de nuestra realidad pastoral. Personalmente nos vemos sin el valor y la energía necesarios para realizar un acto nuevo que resolvería una situación, nos falta imaginación. Y no hay «imaginación, porque nos falta el coraje, porque el corazón no está abierto, no es libre» ${ }^{18}$. Precisamos de pequeños actos arriesgados, aunque tengamos miedo, porque no sabemos qué ocurrirá después, cómo acabará. Pensemos en muchos de los fundadores de órdenes religiosas: Francisco de Asís, Vicente de Paúl, Ignacio de Loyola..., tantos que emprendieron una nueva forma de evangelizar que rompía con la rutina, que no sabían cómo acabaría. Y su esfuerzo y su confianza en el Señor les hizo ayudar a la renovación de la Iglesia de su tiempo y de muchos siglos. Fijándonos en ellos hemos de emprender caminos nuevos, para reconocer en el otro al hermano, para desentumecer nuestro corazón, tan cargado de ansiedades, de inseguridad, porque aplico tal o cual método y no obtiene resultados; de mirada al pasado, no para aprender a seguir adelante sino para ver qué funcionó en otros tiempos y, es seguro, que funcionó aquello que era "palabra de Dios» para las personas que en lugar de pensar ellos en cómo solucionarlo, se pusieron a la escucha del Señor y, aunque les pareciera locura, «echaron las redes en pleno día», cuando los peces no solían entrar en la red y recogieron tantos peces que la barca se hundía.

A veces ocurre que nos sentimos incómodos, no sabemos cómo actuar. Recordemos la parábola de los invitados al banquete de bodas: Seguro que se sintieron halagados por la invitación, pero ¿cómo presentarse ante el rey? Lo más seguro es que hicieran el ridículo. Ellos no estaban acostumbrados al protocolo, ni sabían cómo vestirse para la ocasión, prefieren seguir en la rutina: «arar el campo», "hacer un negocio». Siempre porque tenemos muchas cosas que hacer y eso nos dispensa de pensar, de buscar si hay algo más urgente o más importante. Nos ocurre cuando vemos una necesidad, una escena «dramática», pasamos de largo, porque nos urge llegar pronto a casa y no podemos detenernos. «El labrador que va al campo y el comerciante que se dedica a sus negocios no hacen cosas malas, pero el problema no es el hecho en sí, sino el afán, los deberes ficticios ${ }^{19}$. Como la mujer que, atareada por tener siempre la casa en perfecto orden, se preocupa poco de cómo son sus hijos y su esposo. Hace tantas cosas por ellos... que no tiene tiempo para pensar. Jesús dice «No quieres salir de la rutina de las cosas que te agobian, pero de las que estás contenta, aunque siempre te lamentes con las amigas de que nunca tienes tiempo, de la crisis del

18. Cf. C. M. MARtini, Los ejercicios de san Ignacio a la luz del evangelio de san Mateo, Bilbao 2008, 66.

19. Ibid., 68. 
servicio doméstico, de que debes hacerlo todo y nunca lo consigues, y te conviertes en la heroína de la casa porque estás cargadísima de trabajo» ${ }^{20}$.

En la pastoral vocacional nos suele ocurrir algo parecido: hacemos un precioso proyecto, nos buscamos en Internet o en libros los medios pedagógicos apropiados para llevarlo a término, insistimos a nuestros hermanos y hermanas agentes de pastoral (¿el servicio?) para que nos ayuden, colaboren en llevar a cabo la tarea vocacional de la casa diocesana; acudimos a las reuniones nacionales y/o regionales, convocamos, a nuestra vez, reuniones para ver cómo llevar a cabo el plan. Muchas veces nos quedamos casi solos, únicamente los más fieles, entusiastas o amigos, acuden a ellas y nos queda el regusto de que por más que lo intentamos, las cosas siguen igual..., la casa necesita más manos. Un ejemplo de esta rutina en la que todos caemos es repasar la lista de los temas tratados en nuestras reuniones nacionales, diocesanas y de provincia eclesiástica: siempre giran en torno a lo mismo. Últimamente nos preocupa mucho el equilibrio psico-afectivo de los seminaristas de cara a la ordenación, impelidos por el escándalo de abusos que nos entristecen como Iglesia ${ }^{21}$; el acompañamiento, el discernimiento. Todos ellos elementos muy importantes cara a la formación. Pero... ¿ ¿de quién? Nuestros seminarios siguen con bastante espacio para más gente; jóvenes generosos y entregados no se ven atraídos por la dedicación al ministerio presbiteral; lo que era en otro tiempo motivo de «admiración» y ejemplo para otros jóvenes y niños, pasa desapercibido o sirve de mofa para algunos, o para que se les vea como un poco fuera de este mundo. Y el principio de encarnación es esencial para la formación de los presbíteros del cercano mañana. Cristo se ha encarnado para eso: para estar con nosotros e indicarnos el camino de encuentro con el Padre, si no hubiese colocado unos asideros desde el cielo y... que se salve el que pueda. Y principio de encarnación no significa que hayamos de imitar las «perversiones» de esta sociedad nuestra, sino que hemos de acercarnos para que descubran el gozo de creer en ese Jesús salvador, sencillo y cercano, muy lejos de esa idea pagana que tiene nuestra sociedad del Dios cristiano, al que ven como amenaza para la libertad, bien manipulados por la propaganda oficial. Es preciso que descubran al Padre de la parábola que, se asoma continuamente a la ventana para vislumbrar desde lejos si el hijo que se ha ido, ejerciendo su libertad, se da cuenta de que sólo en la casa del Padre se está bien.

Y es verdad que el ámbito social, los principios de lo «política y socialmente correcto» no ayudan a una respuesta que emane del entorno; pero yo creo que

20. Ibid., 69.

21. Siempre ha sido objeto de preocupación el que los futuros sacerdotes fueran hombres con la madurez necesaria y con la convicción de que ésta no acababa el día de la ordenación, pero los acontecimientos hacen que tratemos estos temas con cierta angustia, lo cual no es el mejor medio de educar en el equilibrio y la madurez. Teresa de Calcuta decía: «La angustia por las vocaciones genera mucha zozobra y ansiedad, pero no trae ninguna vocación». 
hay algo más: no entusiasmamos a los niños con la figura del Jesús amigo, que crece con ellos y no es un fabricante de normas, sino la persona que les ama y se entrega y quiere su felicidad. Nuestras comunidades no tienen, salvo excepciones, conciencia de tales y de que los servicios de la misma han de brotar de ella, para sí o para la Iglesia diocesana o universal. Tenemos una fe muy pasiva y «rutinaria», hacemos lo de siempre en un mundo cambiante, que necesita de signos cercanos que provengan de una forma de vida que se vea. La descripción de la comunidad que nos deja Hch 2, 42-47, no retrata nuestras comunidades actuales, con excepciones. Más parecen individualidades que buscan la propia salvación que personas, conscientes de una misión, que responden a la llamada amorosa de Dios, que quiere hacerles partícipes de su plan de salvación. Estar unidos en la oración, compartir una misión común, tener conciencia de pueblo de hermanos, cuesta mucho en esta competitiva y engañosa sociedad nuestra, a la que no hemos de condenar, sino a la que es preciso amar. $Y$ una forma de amor es orar unidos por los hermanos que se han ido o se han alejado, quizás aburridos porque no encontraban vida en nuestra forma de vivir o tentados por el poder o la codicia, como el hijo que ha pedido al Padre que le dé la herencia (palabra que en griego significa también, la vida ( $\operatorname{cov} \beta ı v$ ) para hacer lo que le venga en gana y no tener nada que ver con él. Recuerda un poco posturas de muchos jóvenes de nuestra sociedad, que reniegan de la fe que les han dejado en herencia «los padres» y se lanzan a otras creencias (en sí mismos, en sus poderes, en la diversión, en la superficialidad) y pueden acabar, como el hijo de la parábola: cuidando cerdos.

Para mover esos corazones, desde la misma situación en la que se encuentren son precisos jóvenes de hoy que respondan desde la conciencia de la sociedad a la que pertenecen a la llamada de Dios, en el sacerdocio y la vida religiosa, pero también en el compromiso laical, proponiendo la singularidad con la que Dios ama a cada uno de nosotros, eligiendo el Amor, aunque tenga que dejar otros «amores», importantes y constructivos también, para hacerlo descubrir a los demás. Y lo más preciso es la «experiencia de Dios» que sólo desde la contemplación y el silencio de la oración se da. Aunque Dios se hace presente cuando y como quiere y cuando lo sientes tan cerca, es verdad que toda la visión negativa del mundo y de los hombres desaparece y se convierte en una mirada tierna desde los «mismos ojos de Dios».

\section{CONVERTIR EL DON EN SERVICIO}

Varias veces se repite en el Documento del Congreso de 1998 la afirmación de que "la vida es un bien recibido que tiende a convertirse en bien donado», parece como un estribillo que quiere quedar preso en el corazón de cada uno de nosotros, para que lo trasmitamos a los demás. Porque la vocación brota ya 
desde la venida a la vida: «El acto creador del Padre tiene la dinámica de una invitación, de una llamada a la vida. el hombre viene a la vida porque es amado, pensado y querido por una Voluntad buena que lo ha preferido a la no existencia» ${ }^{22}$. Es lo que podríamos llamar la «vocación creatural», que explica en la misma raíz, el misterio de la vida del hombre. Esta vocación se concretará en la «llamada a ser sujeto de relación con Dios, a estar con Él». Es la «vocación religiosa» que da sentido pleno a la vida: "La vida es la obra maestra del amor creador de Dios y es en sí misma una llamada a amar. Don recibido que, por naturaleza, tiende a convertirse en bien dado», y más adelante: «El hombre será feliz y plenamente realizado estando en su puesto» ${ }^{23}$.

Un paso más en la llamada está en la celebración a la vida en el Bautismo. Es la vocación cristiana. «En este sacramento el Padre se inclina con ternura solícita sobre la criatura, hijo o hija del amor de un hombre y de una mujer, para bendecir el fruto de aquel amor y hacerlo plenamente suyo. Nada ni nadie podrá cancelar jamás esta vocación (...). La fidelidad al bautismo significa, por tanto, mirar a lo alto como hijos, para llevar a cabo el discernimiento de su voluntad sobre la propia vida y el propio futuro» ${ }^{24}$. Esta vocación cristiana se concretará en vocación apostólica en cualquiera de las modalidades de servicio, antes citadas: vida laical, soltería o matrimonio o laicos consagrados, vida religiosa, activa o contemplativa y ministerio ordenado. Todos ellos parte del servicio que la Iglesia, como mediadora del Reino, cumple en cada época de la historia. El seguimiento de Cristo no es una llamada a la propia santificación, al menos no en exclusiva, sino que la propia santificación se realiza en el ejercicio del servicioministerio al que se ha sido llamado, in-vocado como llamado a... y como pedido y concretado en la oración, la vocación nace de la in-vocación, y el acierto en la respuesta tiene mucho que ver con el silencio orante que ha llevado a entregar la vida en servicio a los demás, sea cual sea la modalidad de vocación a la que hayamos sido llamados, siempre desde el amor de Dios que quiere la máxima felicidad, ya en esta vida, para cada uno de sus hijos. Está claro que vocación es igual a misión y que vocación es don.

Hay un texto de Nueva Vocaciones que siempre que lo leo me impresiona y me hace descubrir el secreto de la vida. Está en el n. 36b, dice así: «Si es don, será plenamente él mismo sólo si se realiza en la perspectiva del darse; será feliz a condición de respetar esa naturaleza suya. Podrá hacer la opción que quiera, pero siempre en la lógica del don; de lo contrario se convertirá en un contraste consigo mismo, una realidad 'monstruosa'; será libre de elegir la orientación específica que quiera, pero no será libre de pensarse fuera de la lógica del don». Llamada al servicio, heredera de toda una historia de entrega de la Iglesia 
al servicio de los hombres, llamada que necesita la «formación» que da el propio Jesús para ser de veras el servicio que los hombres de cada tiempo necesitan, porque la «lógica del don» es la única que Jesús conoce y trasmite a sus discípulos. Su servicio en la cruz y, especialmente, en la Resurrección que es el comienzo de la nueva vida, de la nueva alianza de Dios con el pueblo nuevo, y hay que subrayar el adjetivo nuevo, ya que éste nos obliga a estar siempre atentos, en camino, sin dejarnos llevar ni por desalientos, porque parece que las cosas no van según nuestros planes, ni de excesivos optimismos, cuando salen conforme a lo planificado. Es Dios quien actúa a través de nosotros y más que preguntarnos: ¿qué podemos hacer por Dios?, es preciso que nos preguntemos: ¿cómo podemos hacer para dejar que Dios haga en nosotros? Es esa disponibilidad la que nos llevará a una respuesta en misión, serena y contemplativa, sin agobios ni angustias, puestos al servicio de los otros con la seguridad que da la escucha de lo que Dios quiere y que tenemos expresada en la Palabra. Esa Palabra que hemos de encarnar en cada momento de la historia.

Concluiría diciendo que la pastoral vocacional hoy se enraíza en el «estar con Él, para aprender de Él y después comunicarlo a los otros». En responder a ese «venid y ved» que nos sitúa no en teorías sino en la realidad de un Dios amor que por amor nos crea y en amor nos redime y por amor nos llama a que desarrollemos en cada tiempo la única misión. Los medios que empleemos, pedagógicos o teológicos, serán sólo plataformas si de verdad llevan al encuentro con Él, Señor de toda llamada, y transforman desde dentro a la persona, que, descubriendo que todo amor de donación lleva al amor de Dios, no duda en entregar su vida para esta misión y se da cuenta de que hoy, en la Iglesia, hacen falta jóvenes que también dediquen su vida al servicio a tiempo completo, de manera especial al ministerio ordenado, a ser servidores del pueblo, por su santidad (parecidos a Dios) y por su sencillez en la entrega, conscientes de que la vida sólo en ésta adquiere su sentido pleno: Ser para los otros, porque el don recibido ha de convertirse en bien dado.

\section{A MANERA DE CONCLUSIÓN}

En el Documento citado se dice: «Se hace animación vocacional sólo por contagio, por contacto directo, porque el corazón está lleno y la experiencia de la belleza continúa cautivando» ${ }^{25}$. Me parece un subrayado muy importante, que es novedad en esta sociedad nuestra en la que parece que la cultura vocacional está proscrita, como si el hombre fuese una casualidad y no producto del amor de Dios. Pero no otra era la «metodología» que en la «sociedad de cristiandad» se tenía: nos sentíamos atraídos por la vida de tantos sacerdotes y gentes cer-

25. NVNE, 34, § 5. 
canas a la comunidad eclesial que nos llevaban a superar las dificultades que, naturalmente, teníamos de todo tipo: afectivo, social, de aspiraciones humanas, de forma de vida (la soledad era uno de los elementos de crisis, el hecho de no tener hijos y ser padre de todos). Pero nos ayudaba el mismo ambiente en el que vivíamos, la necesidad de sustituir a aquellos que animaban nuestras comunidades... Era, ciertamente, una animación vocacional por contagio, en otra época, pero considero que es la única forma y sigue siendo hoy el «método» más empleado. Cuando alguien en búsqueda ve una vida plena se pregunta el porqué y empieza a buscar para llenar el propio corazón y ayudar a descubrir a los demás lo que él ha descubierto. Pero ese corazón tiene que estar llena de la belleza que Dios comunica, ante la cual toda otra belleza pierde ruido.

Otro elemento base es que la vocacionalidad sea de toda la comunidad. «La pastoral vocacional unitaria se funda sobre la vocacionalidad de la Iglesia y de cada vida humana como llamada y como respuesta. Esta vocacionalidad es el fundamento del compromiso unitario de toda la Iglesia por todas las vocaciones $y$, en particular, por las vocaciones de especial consagración ${ }^{26}$. Importante hacer hincapié en la Iglesia toda ella llamada y no tener miedo de que sea considerado como vocación específica, o modalidad vocacional, todo mi misterio a favor de la comunidad. «Hay -nos dice el Documento-quien teme que la ampliación del concepto vocación pueda perjudicar a la específica promoción de las vocaciones al sacerdocio y a la vida consagrada; en la realidad sucede exactamente lo contrario». Una comunidad con conciencia y cultura vocacional, integrada y variada en sus servicios y ministerios, es capaz de generar con mayor fidelidad aquellos que necesita para su vida evangelizadora al interior de ella misma y a la ejemplaridad para los demás, es una comunidad que evangeliza por contagio, por estar plenamente llena y mostrar la belleza del servicio al Señor.

Estoy convencido de que si vamos creando estas comunidades, si nuestros métodos no los convertimos en fines, sino permanecen como medios, si lo importante es transmitir la «vida», nuestra pastoral vocacional crecerá según el «corazón de Dios» y cumplirá su misión: proporcionar a nuestras comunidades todos los servicios que necesitan para hacer visible la presencia de Dios entre nosotros. No debe tentarnos el miedo, hemos de caminar en la seguridad que da el saber que la obra es de Dios y no nuestra, pero, para que así sea, hemos de poner nuestra confianza y escucha en ese Dios que no dejará huérfana a su Iglesia. Pedimos a María que nos ayude con su valiosa intercesión ante el Hijo que la hará llegar al Padre en el Espíritu.

26. Ibid., 22; Instrumentum Laboris, 58. 